\title{
Software Modernization and Replacement Decision Making in Industry: A Qualitative Study
}

\author{
Miia-Maarit Saarelainen, Jarmo J. Ahonen \\ Department of Computer Science \\ University of Kuopio \\ P.O. Box 1627, Fl-70211 Kuopio, Finland \\ \{miia.saarelainen, jarmo.ahonen\}@uku.fi \\ $\begin{aligned} & \text { Heikki Lintinen, Jussi Koskinen, Irja Kankaanpää, Henna Sivula, Päivi Juutilainen, and Tero Tilus } \\ & \text { Information Technology Research Institute } \\ & \text { University of Jyväskylä }\end{aligned}$
P.O. Box 35, Fl-40014 Jyväskylä, Finland
\{heikki.lintinen, jussi.koskinen, irja.kankaanpaa, henna.sivula, paivi.juutilainen, tero.tilus\}@titu.jyu.fi
}

\begin{abstract}
Software modernization and replacement decisions are crucial to many organizations. They affect greatly to the success and well being of the organizations and their people. The decisions like that are usually presumed to be rational and based on facts. These decisions and how they are made tell much about the decision makers and the decision making tools available to them. Interviews of 29 software modernization decision makers or senior experts were analyzed in order to find out how the decisions were made and what models and tools were used. It turned out that decisions are not as rational as supposed. Intuition is the dominant factor in decision making. Formal software engineering oriented decision support methods are not used. Most decision makers did not see intuition as a preferable way to make decisions. This might be because the preferred values are rationality and formality. Since the use of intuition is not particularly valued it is not necessarily admitted or documented either. However, truthful description and justification of decisions is important both from the practical and ethical point of views.
\end{abstract}

Keywords: software modernization, decision making, qualitative study, rationality, intuition

\section{INTRODUCTION}

The modernization and replacement decisions of information systems often have crucial impacts on modern organizations. Those decisions may cause remarkable changes in the life of the endusers of those systems and even in the general success of the organization in question. Those decisions should be as ethical and traceable as possible due to the fact that a single decision may lead to huge economical losses and the worsened life of many people. Those decisions may, of course, lead to economical miracles and general success. The positive possibility does not, however, weaken the ethical standards and traceability that should be required from such decisions.

The old information systems that are modernized or replaced are normally called legacy systems. Those systems are, in many cases, vital to the organization that uses them. They are, however, hard and expensive to manage (Bennett and Rajlich 2000). It has been realized that the maintenance and evolution costs of legacy systems are normally somewhat between $40 \%$ and $90 \%$ of the total costs of the life-cycle of the system (Foster 1993)(Glass 2003)(Seacord, Plakosh and Lewis 2003). A brand new information system that is installed today may be a legacy system in the future. 
The vital role of legacy systems and the extensive costs caused by maintenance and evolution of such systems require that the decisions made regarding those systems are well-thought, ethically defendable, understandable and based on facts. In other words, such important decisions are required to be rational and traceable. Rationaly requires, in many cases, the use of formal decision making procedures which are based on hard facts. The traceability requires that every phase and reason for the decision be understood afterwards. At least a couple of software reengineering and modernization approaches which should satisfy these requirements have been proposed in the literature, see e.g. (Sneed 1995) and (De Lucia, Fasolino and Pompella 2001).

The relatively high number of horror stories of information system decisions should make one wonder: Is the real-world decision making really that rational and traceable? The question is especially interesting because the accepted way to make decisions in the current business world requires that the decisions are based on objective analysis of real facts. We do, however, know that in the concrete world many decisions require intuition, which can bee seen as compressed expertise that allows the expert to use his/her experiences and knowledge in a fast and adaptive way (Sauter 1999). Therefore we should admit that intuitive and formal decision-making can be seen as the two sides of expert judgment (Simon 1987)(Patton 2003)(Sadler-Smith and Shefy 2004)(Miller and Ireland 2005).

The results of the study were surprising. The reality is not as rosy as one would assume when reading the quidelines stated in the Software Engineering Code of Ethics and Professional Practices (Gotterbarn, Miller and Rogerson 1999). The role of rational and traceable approaches to decision making is astoundingly insignificant in the real-world, as will be seen in the rest of this article. The results show that the role of intuition is dominant and the existing rational approaches are not used in the real-world decision making. This will propose remarkable challenges to both the academia and industry if traceability and ethicality of decisions will be required.

\section{ARE REPLACEMENT AND MODERNIZATION DECISIONS RATIONAL AND TRACEABLE?}

Professional life includes many decision making situations. In modern software engineering profession those decisions are supposed to be rational and based on facts. The rational decision making is the backbone of the theory of economic decision making (Simon 1979). The software engineering decision making tools and models are more or less intentionally based on common decision making theories and strategies, like the expected utility theory (von Neumann and Morgenstern 1944) and the prospect theory (Kahneman and Tversky 1979). The conceptual model of software engineering decision maker is based on the idea of rational and intelligent people making decisions based on hard data and careful use of decision making tools and economic calculations. The software engineering decision making tools and methods are clearly based on that concept of decision making.

Those models are mainly based on the idea of making rational decisions possible by providing tools by which the rationality can be achieved. Such models and tools may be grouped into general software cost estimation models and software maintenance estimation or decision models. Those software cost estimation models include models such as Boehm's COCOMO (Boehm 1981) and COCOMO-II (Boehm, Horowitz, Madachy, Reifer, Clark, Steece, Brown, Chulani and Abts 2000), Albrecht's Function Point Analysis (Albrecht and Gaffney 1983), McCabe's Cyclomatic Complexity (McCabe 1976) and Halstead's method (Halstead 1977). Several models can be used to support rational decision making in the field of software engineering. Models can be used to estimate for example maintainability (Coleman, Ash, Lowther and Oman 1994)(Di Lucca, Fasolino, Tramontana and Visaggio 2004), software complexity effects (Gibson and Senn 1989)(De Lucia, Di Penta, Stefanucci and Venturi 2002), general maintenance cost drivers (Niessink and van Vliet 1998) and reengineering effects and strategies (Sneed 1995)(Warren and Ransom 2002).

The concept of the rational and traceable decisions is necessary because many of the softwarerelated decisions are very crucial for various reasons including money and human well-being. For example the decision to replace an old system with a brand new one may be of extreme 
economical importance to the organization and its future. If the decision is incorrect, it could lead to a major economic loss and business failures. Also these decisions have a remarkable influence on the people who are working in the software end-user organizations. Therefore, these kind of decisions should be made according to rational decision process and the rationality should be able to be analyzed afterwards. The use of documented and at least semi-forman decision making frameworks is the expected way of decision making.

If the decision making in the field of software engineering was as rational and ethical and traceable as it should, then the number of software engineering horror stories should be much smaller than it is. The amount of horror stories do, however, make one to wonder whether our models and tools are lacking or whether professional decision making is something else than one would assume. Therefore it is recommended to have a closer look at the actual decision making practices found in the industry: Do industrial decision makers perform rational, ethical and traceable decision making?

In the reported study interviews of professionals were analyzed in order to get a better understanding of the decision making strategies, tools, and methods of experienced professionals. The main aim of the study was to get at least a better picture of the decision factors with the actual tools and techniques used by professionals.

\section{HOW THE STUDY WAS PERFORMED AND A BRIEF ANALYSIS OF THE DATA}

The material of the study consists of 29 interviews of people who have relevant roles in software engineering related decision making, especially software modernization or replacement decisions. The material was collected by one-to-one interviews of a semi-structured form. The interviews took place between August 2003 and February 2004. The interviewed people were found with the snowball sampling. That approach to sampling offers an established method for identifying and contacting populations which are hard to reach (Vogt 1998). The snowball starts with a core set of persons who are asked to name the best people to answer the posed questions. The named persons are contacted, interviewed, and so the snowball grows. In this study the sampling started from three experts.

Interviewees were from 8 different organizations. There were 3 software supplier organizations and 5 software end-user organizations. From 29 interviewees 12 worked within software supplier organizations and 17 within end-user organizations. Their average working experience with information systems was 19 years and with modernization decision making or argumentation 8 years. Their average age was 48 years. There were 4 people performing the interviews, which has a slight effect on the flow of the interviews.

Interviews contained total of 43 questions of which 15 questions were about background information and 28 questions about modernizations and decision making. The questions covered for example the following areas:

- The professional background of the interviewee.

- Who makes the modernization decisions?

- Are there some guidelines or procedures for decision making and what type they are?

- What different aspects of decision making are used?

- Are the decisions based on methods and what methods are used?

Additional questions were asked from some of the interviewees. Interviews were recorded with permission and afterwards transcribed. Transcribed interviews, which included questions, were about 141600 words, so the average length for each interview was about 4880 words. The language of the interviews was Finnish. An overview of the interview questionnaire and the first level analysis of the interviews has been presented in (Koskinen, Lintinen, Ahonen, Tilus and Sivula 2005). That analysis will not be repeated here.

In a study like the reported one it is typical that different methods are simultaneously used and methods are used together (Eskola and Suoranta 2000). The research methods used in this 
study are quantification, identification of themes and use of discourse analysis. Quantification is a method where quantitative method is used with qualitative data. It usually means that occurrences of different cases are counted. In theming the data is divided into different themes and in discourse analysis the different meanings, which are given in text, are studied and analyzed.

In the analysis only parts of the whole interviews were used. Those parts were the ones related to decision making. According to the background assumptions the decision making process was assumed to be professional, rational, traceable and ethical. That assumption was made because all of the interviewees were in positions in which they often make decisions that may lead to significant use of resources and long-time software engineering commitments. The analysis focused on those interview questions that were related to the decision making as a process or the various parts of the decision making process. General themes have been identified earlier as reported in (Koskinen et al. 2005). The analyzed questions were (the numbers of the questions presented below do not reflect the numbers of the corresponding questions in the original interview):

Q1: To what extent are the modernization decisions based on intuition?

Q2: To what extent formal or numerical methods are used to justify the modernization decisions?

Q3: Which methods are used to justify the modernization decisions?

Q4: To what extent there is a need for the numerical description of the potential benefits of modernization?

Q5: To what extent the calculation of the potential costs has been possible in the previous modernization decisions?

In the first phase of the analysis (quantification and making themes) the decision making processes were analyzed as they were described by the interviewees. The basic idea of the analysis was to find answers to the analysis questions:

$\mathrm{A}$ : Is the use of intuition directly admitted?

$\mathrm{B}$ : Is the use of intuition admitted later on in the interview?

The themes were the direct admission of use and the later admission of use. The analysis of the direct admission and the later admission was performed by creating a table in which the interviews were classified according to the transcripts. The resulting table is shown as Table 1 . The table is mainly based on question Q1.

The analysis question $B$ (later admitted use of intuition) was answered by analysing the answers to the interview questions Q2-Q5. In several cases it turned out that an interviewee had given a negative answer for the analysis question A, but later said e.g. "I don't think we use any methods. I have not seen any.". In such case the answer to the analysis question B was considered positive (use on intuition admitted). In the same manner a negative answer to the analysis question $A$ and the later statement "Yes, we always calculate." was considered as a negative answer to the analysis question B. The results of that classification are shown in Table 2.

The second phase of the analysis was discursive analysis. Discursive analysis was used in order to find out

C: Is the use of intuition evident based on the analysis of the transcripted texts?

D: What formal, i.e. numeric or quantitative, methods or tools or techniques are used for decision support?

The questions $A, B, C$, and $D$ were decided to be sufficient in order to reveal the underlying formal or intuitive nature of the decision making processes of the interviewees.

In this type of analysis the researchers try to see or understand what lies between the lines. A careful examination of the actual sayings of the interviewees and general impressions based on the analysis of the transcripts is the main tool for eliciting the answers. For example expressions 
TABLE 1: Direct admissions regarding the use of intuition.

\begin{tabular}{|c|c|c|}
\hline Interviewee & Yes & No \\
\hline 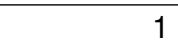 & & It is not used. It can't be used \\
\hline 2 & $\begin{array}{l}\text { Yes it is used. It is occasional, but it } \\
\text { happens. }\end{array}$ & \\
\hline 3 & & $\begin{array}{l}\text { I think quite little. That's the picture I } \\
\text { have. }\end{array}$ \\
\hline 4 & & Not very much. \\
\hline 5 & $\begin{array}{l}\text { They are not based on rational } \\
\text { decision making. I would say quite } \\
\text { much. }\end{array}$ & \\
\hline 6 & $1 / 3$ could be. & \\
\hline 7 & & In my opinion not at all. \\
\hline 8 & & I don't think it is done. \\
\hline 9 & Maybe $30 \%$. & \\
\hline 10 & $\begin{array}{l}\text { It happens, earlier it happened even } \\
\text { more. }\end{array}$ & \\
\hline 11 & & They are not done based on intuition. \\
\hline 12 & $\begin{array}{l}\text { Let's say it is based quite much on } \\
\text { intuition. }\end{array}$ & \\
\hline 13 & & Well, they are not worth of doing. \\
\hline 14 & & $\begin{array}{l}\text {... that in the end using the intuition is } \\
\text { quite insignificant. }\end{array}$ \\
\hline 15 & $\begin{array}{l}\text { Well, unfortunately it is used quite } \\
\text { much in our organization. }\end{array}$ & \\
\hline 16 & & $\begin{array}{l}\text { Well, it is not certainly done based on } \\
\text { that. }\end{array}$ \\
\hline 17 & & Well, not in our organization, I think. \\
\hline 18 & Too much. & \\
\hline 19 & & $\begin{array}{l}\text { Maybe it is 8-. (when } 10 \text { means never, } \\
4 \text { always) }\end{array}$ \\
\hline 20 & Well, it exists in some volume. & \\
\hline 21 & & $\begin{array}{l}\text { I have not seen for a long time a } \\
\text { solution which is made based on 'this } \\
\text { feels good' -idea. }\end{array}$ \\
\hline 22 & & I don't think at all. \\
\hline 23 & $\begin{array}{l}\text {...that we just have to guess what } \\
\text { direction to go now. }\end{array}$ & \\
\hline 24 & Well, it does exist. & \\
\hline 25 & & In today's world quite little, I think. \\
\hline 26 & Well, they have been done. & \\
\hline 27 & & Well, I don't think so. \\
\hline 28 & & Not at the upper level. \\
\hline 29 & & I think it hasn't been done. \\
\hline
\end{tabular}


TABLE 2: The role of intuition is revealed or admitted later on.

\begin{tabular}{|c|c|c|}
\hline Interviewee & Yes & No \\
\hline 1 & & Yes, we always calculate. \\
\hline 3 & $\begin{array}{l}\text { We got this rule of thumb what it could } \\
\text { be. }\end{array}$ & \\
\hline 4 & $\begin{array}{l}\text { Really used? It is the rule of thumb } \\
\text { that we calculate something. }\end{array}$ & \\
\hline 7 & $\begin{array}{l}\text { I don't think we use any quantitative } \\
\text { methods. I have not seen any. }\end{array}$ & \\
\hline 8 & & We do calculation of costs. \\
\hline 11 & & $\begin{array}{l}\text { Everything we do if it is something we } \\
\text { can calculate. }\end{array}$ \\
\hline 13 & $\begin{array}{l}\text { There is not really organized, } \\
\text { calculation-based, but some } \\
\text { economic considerations. }\end{array}$ & \\
\hline 14 & $\begin{array}{l}\text { I don't know how much there is real } \\
\text { scientific base on those, but we have } \\
\text { hands on experience. }\end{array}$ & \\
\hline 16 & & $\begin{array}{l}\text { In theory, we have used quantitative } \\
\text { methods. }\end{array}$ \\
\hline 17 & & $\begin{array}{l}\text { Of course we calculate what is } \\
\text { affordable, how much we need to } \\
\text { sell... }\end{array}$ \\
\hline 19 & & Of course what it costs. \\
\hline 21 & $\begin{array}{l}\text { I think we don't have any civilized } \\
\text { models to base on. }\end{array}$ & \\
\hline 22 & & $\begin{array}{l}\text { It is very normal that we calculate } \\
\text { working hours, euros... }\end{array}$ \\
\hline 25 & & $\begin{array}{l}\text { We have to show assessment criteria } \\
\text { very exactly. }\end{array}$ \\
\hline 27 & & $\begin{array}{l}\text { We should use. There is no decision } \\
\text { where we don't count pay back time. }\end{array}$ \\
\hline 28 & $\begin{array}{l}\text {...everything is based on word } \\
\text { mongering. }\end{array}$ & \\
\hline 29 & $\begin{array}{l}\text { We don't use them. (when asked } \\
\text { about using quantitative methods) }\end{array}$ & \\
\hline
\end{tabular}

like "We should use (quantitative methods)." and "There is nothing else than illusion" tell their story about missing formal methods in the real decision making processes or the methods' lack of suitability for the real world.

It is worth noting that the interviewee's use of language revealed the use of intuitition. For example the interviewees could not name or describe the methods which were used or they used phrases like "We try to use quantitative methods" or "There is some price and then they give some value to it" or "We can do counting based on supposition and on experience and on things and values we had learnt". When the interviewee said, that they try to use quantitative methods, it clearly tells that the decisions are not based on formal methods. Personnel of that particular organization would like to use or they should use quantitative methods, but for some reasons it is not the way they usually work.

Cases where the interviewee used words like "some" and "something" reveal that they do not have the information and the methods required for formal decision making. In those cases the interviewee knew that quantitative methods were the expected way of assessment, but they are not used. Similarly answers which tell that something "is based on supposition or experience" 
it can be concluded that decision making is based on intuition and fuzzy reasoning, not on formal methods. In every interview there were clear indicators that showed the dominant role of intuition in decision making. In other words, every one of the interviewed decision makers relied on intuition, not formal methods or procedures in their decision making. The decisions were not really backed up with hard, fact based data and evaluations - the decisions were based on the "gut feeling" of the decision making individual.

One of the most interesting results from the analysis was that the interviewees were not able to name or describe any formal or semi-formal decision-making method. The most formal mentioned approaches were return on investment (ROI), cost estimation, and giving grades to different options. In most cases even that level of method definition was lacking. In addition to that, the vague methods mentioned by the interviewees are based on intuition - at least in the forms they were mentioned.

\section{UNDERSTANDING THE RESULTS}

When asked if the modernization decisions were based on intuition, 12 of 29 interviewees admitted it straight away in some level. Some of those interviewees said that they use intuition too much, some of them said that about $30 \%$ of decisions are based on intuition and some of them said that it happens. But a closer analysis of the answers for the later questions, which handled quantitative methods and quantification, reveals that 20 from 29 admitted intuition at that point. Admission could be seen in answers like "Really used? It is mostly the rule of thumb, that we count something" (when asked if some methods are used) or "I don't know how much there is real scientific base, but we have hands on experience". In other words, closer analysis showed beyond reasonable doubt that decision making relied on intuition, not on rational, fact analyzing methods or working procedures.

It must be noted that the data analyzed in the reported study is fairly limited and the results may not be generalizable. It is reasonable, however, to consider the result fairly descriptive for Finland due to the reasonably uniform educational background and experience of the interviewees. For other countries the results may also be reasonably accurate. That accuracy can be assumed because the age of people in similar decision making positions is about the same in different countries and the educational background (actually the contents of the education, most likely master's degree in computer science, engineering or business economics) is surprisingly similar in industrialized western societies.

According to the data and its analysis it is clear that rational decision making methods were not widely used. Interviewees described some methods like giving grades to different solutions or calculating costs, but they could not name or describe their methods very clearly or systematically. At least in the case of the interviewees intuition has the dominant role in making software replacement or modernization decisions. That is contrary to the normal expectations that are held regarding economically significant technical decisions.

It is very interesting that most of the interviewees did not admit using intuition directly although they used it. It tells that somehow they see intuition as an unfavorable way to make decisions. It can be seen from the answers that most of the interviewees do not consider intuition as a part of normal, recommended decision making process and they do not see intuition as a professional way to make decisions as the literature states (Simon 1979)(Seacord et al. 2003)(Sadler-Smith and Shefy 2004).

The state of the affairs seems to be that rational methods described in the literature are not in everyday use in information technology supplier or buyer organizations. In this study decision making is found out to be based on various mixes of intuition, calculation and estimation - mixes in which intuition is in the dominant role. However, the interviewed decision makers wanted to see that the decisions made in their organization are rational and formal. It even seems to be the case that they were very reluctant to admit the lack of rational fact-based methods and the reliance on intuition to themselves. 
It should, however, be noted that the concept of rationality has been questioned in some earlier studies, see e.g. (Parnas and Clements 1986). It could be that rational decision making is not as common human activity as expected. In order to understand the actual decision making and the possibility of creating useful tools and models for decision making a good understanding of the decision criteria should be obtained. Such understanding could provide valuable insights to the actual use of the formal making tools, methodologies and economic measures. For example Herbert Simon suggests that a good manager needs both analytical, rational skills and intuition (Simon 1987). He states: "Behaving like a manager means having command of the whole range of management skills and applying them as they become appropriate". Also, the recent scientific researches are bringing up the same idea (Patton 2003)(Sadler-Smith and Shefy 2004)(Miller and Ireland 2005).

This does not mean that we should forget rationality and formality; it means that we should not forget or deny the role of intuition. It may become very dangerous if rationality is faked and real reasons behind the decisions are attempted to be hidden. This may lead to faulty decisions (Cook, Elder and Ward 1997). Also, it is clear that faking makes the decisions non-traceable (Parnas 1998).

\section{DISCUSSION}

Software engineering related decision making is an interesting phenomenon. The common assumption is that those decisions should be performed by using rational and formal decision making tools, methods and processes - the software engineering literature boasts an abundance of different tools and methods which could be used in order to provide rational support for the decision maker. Those tools and methods are not, however, widely used in the real world.

The most interesting finding provided by the reported study is that the decision makers do not see intuition as a correct way of decision making. Yet they are using it extensively. That makes it very important to find out why rational methods are not widely used and why intuition is seen as an improper means to justify decisions. One reason could be that methods described in the literature are too problematic to be used in the real world. For example, in today's hectic business environment collecting the data needed for a specific analytical method might be too difficult and time-consuming (Patton 2003). Also the amount of the data needed for the righteous decisions might be too difficult to reach. The reason why intuition is seen as a bad decision making might be because of the education and traditions. In business, management and computer science education rationality is seen as the only way of making the decisions (Sadler-Smith and Shefy 2004) and therefore the values of software engineers and decision makers favor pure reason and formal decisions. It is also worth raising the question whether there is a way to shorten the gap between research world and the business world (Parnas 1998)(Glass 2003) regarding the tools and methods for actual decision making. Obviously research based on the real world cases is needed in this area.

Due to the nature and the limited geographical area of this reported study, the results of the study may be less representative than the authors of this article assume. Anyway, results of this study can be used as a basis of the later discussion and studies of modernization decision making.

The role of intuition should be brought out more clearly in decision making. It is dangerous to use intuition and then deny using it. In some cases it is typical to find the justification for decisions after the decisions are made (Parnas and Clements 1986). This may lead to the situations where decision making and its justification are thought to be rational and then the final results are surprising and not wanted. This makes the decisions and the decision process nontraceable. Non-traceability makes the important learning from the failures impossible (Miller and Ireland 2005). How can one learn something if he/she does not know what happened and how it happened? That kind of behavior makes also the later rational decision making and decision making process improvements difficult. How can the processes be improved if the experiments and documentations of the previous processes do not correspond to the reality? 
It is important that the decisions and the criteria behind the decisions are described honestly. Without truthful justification and description decisions can not be ethical and consequently they do not correspond to expectations of the world around us. Such decision making is not an acceptable policy for software engineering professionals.

\section{REFERENCES}

Albrecht, A. and Gaffney, J. (1983) Software function, source lines of code, and development effort prediction A software science validation, IEEE Transactions on Software Engineering 9(6), 639-648.

Bennett, K. H. and Rajlich, V. T. (2000) Software maintenance and evolution a roadmap, Proceedings of the Conference on the Future of Software Engineering, ACM, ACM Press, Limerick, Ireland, pp. 73-87.

Boehm, B. (1981) Software Engineering Economics, Prentice Hall.

Boehm, B., Horowitz, E., Madachy, R., Reifer, D., Clark, B., Steece, B., Brown, A., Chulani, S. and Abts, C. (2000) Software Cost Estimation with COCOMO II, Prentice Hall.

Coleman, D., Ash, D., Lowther, B. and Oman, P. 1994, Using metrics to evaluate software system maintainability, Computer 27(8), 44-49.

Cook, M. J., Elder, L. and Ward, G. (1997) Decision making, planning, and teams, IEE Colloquium on Computer Mediated Complex Supervisory and Decision Making in Teams, Digest, number 137, pp. 5/1-5/22.

De Lucia, A., Di Penta, M., Stefanucci, S. and Venturi, G. (2002) Early effort estimation of massive maintenance process, Proceedings of the IEEE International Conference on Software Maintenance, ICSM 2002, IEEE Computer Society, pp. 234-237.

De Lucia, A., Fasolino, A. R. and Pompella, E. (2001) A decisional framework for legacy system management, Proceedings of the IEEE International Conference on Software Maintenance, ICSM 2001, pp. 642-651.

Di Lucca, G. A., Fasolino, A. R., Tramontana, P. and Visaggio, C. (2004) Towards the definition of a maintainability model for web applications, Proceedings of the 8th European Conference on Software Maintenance and Reengineering, IEEE Computer Society, pp. 279-287.

Eskola, J. and Suoranta, J. (2000) Introduction to Qualitative Research (in Finnish: Johdatus laadulliseen tutkimukseen), 6th edn, Vastapaino.

Foster, J. (1993) Cost Factors in Software Maintenance, PhD thesis, University of Durham, Durham, UK.

Gibson, V. and Senn, J. (1989) System structure and software maintenance performance, Communications of the ACM 32(3), 347-358.

Glass, R. L. (2003) Facts and Fallacies of Software Engineering, Addison-Wesley, New York.

Gotterbarn, D., Miller, K. and Rogerson, S. (1999) Software engineering code of ethics is approved, Communications of the ACM 42(10), 102-107.

Halstead, M. (1977) Elements of Software Science, North-Holland.

Kahneman, D. and Tversky, A. (1979) Prospect theory: An analysis of decision under risk, Econometrica 47(2), 263-291.

Koskinen, J., Lintinen, H., Ahonen, J. J., Tilus, T. and Sivula, H. (2005) Empirical study of industrial decision making for software modernizations, in R. Jeffery (ed.), 2005 International Symposium on Empirical Software Engineering, ISESE 2005, IEEE Press, pp. 235-244.

McCabe, T. (1976) A complexity measure, IEEE Transactions on Software Engineering 2(4), 308320.

Miller, C. C. and Ireland, R. D. (2005) Intuition in strategic decision making: Friend or foe in the fast-paced 21st century, Academy of Management Executive 19(1), 19-30.

Niessink, F. and van Vliet, H. (1998) Two case studies in measuring software maintenance effort, Proceedings of the International Conference on Software Maintenance, IEEE Press, pp. 7685.

Parnas, D. L. (1998) Successful software engineering research, ACM SIGSOFT Software Engineering Notes 23(3), 251-257.

Parnas, D. L. and Clements, P. C. (1986) A rational design process: How and why to fake it, IEEE Transactions on Software Engineering 12(2), 251-257.

Patton, J. R. (2003) Intuition in decisions, Management Decision 41(10), 989-996. 
Sadler-Smith, E. and Shefy, E. (2004) The intuitive executive: Understanding and applying 'gut feel' in decision making, Academy of Management Executive 18(4), 76-91.

Sauter, V. (1999) Intuitive decision-making, Communications of the ACM 42(6), 109-115.

Seacord, R. C., Plakosh, D. and Lewis, G. A. (2003) Modernizing Legacy Systems, The SEI Series in Software Engineering, Addison-Wesley.

Simon, H. A. (1979) Rational decision making in business organizations, American Economic Review 69(4), 493-513.

Simon, H. A. (1987) Making management decisions: the role of intuition and emotion, Academy of Management Executive 1(1), 57-64.

Sneed, H. (1995) Planning the reengineering of legacy systems, IEEE Software 12(1), 24-34.

Vogt, W. P. (1998) Dictionary of Statistics and Methodology: A Nontechnical Guide for the Social Sciences, Sage, London, UK.

von Neumann, J. and Morgenstern, O. (1944) Theory of Games and Economic Behavior, Princeton.

Warren, I. and Ransom, J. (2002) Renaissance: a method to support software system evolution, Proceedings of the 26th Annual International Computer Software and Applications Conference, IEEE Press, pp. 415-420. 